\title{
Dynamic Modeling and Simulation of a Stand-alone DC Hybrid Microgrid for a Base Transceiver Station in Nigeria
}

\author{
Cyprian Oton and M. Tariq Iqbal
}

\begin{abstract}
This work considers the dynamic modeling and simulation of a DC hybrid power system for a rural base transceiver station in Nigeria currently being powered by an $\mathrm{AC}$ diesel generator (DG). The transient behaviour of the system is studied under varying solar irradiation to ascertain the stability of the power supplied to the sensitive telecommunication equipment. Each component of the system is designed and simulated in a MATLAB/Simulink environment and connected to form the whole system. A permanent Magnet DC diesel generator is used as back-up power for the system. A detailed presentation of the solar array, buck converter, battery storage system, battery controller, diesel generator and the load are presented in this paper. The result shows a stable power output to the load at rated voltage of $48 \mathrm{~V}$.
\end{abstract}

Index Terms - Base Transceiver station; DC microgrid; Dynamic simulation; MATLAB/Simulink.

\section{INTRODUCTION}

The quest for energy in rural areas and remote locations where conventional grid is unavailable has propelled the deployment of distributed energy resources to meet the energy needs of these locations in the form of micro and nano grids. These grids can be for a community or it can be application specific. This arrangement mostly utilizes conventional diesel generator because of the low initial capital expenditure (CAPEX) but very high operating expenditure (OPEX). Example of the application/operation that relies heavily on power supply is the base transceiver station site.

Energy has continued to be a major challenge for developing and underdeveloped countries around the world while mobile communication industry has continued to experience tremendous growth in these countries. With this growth comes the need for more base station sites to be built, and some in very remote location with no electricity. With the growing concerns of the negative environmental impact of these conventional means of power generation, there is urgent need to switch to a renewable, environmentally friendly means of power generation. Also, with the current testing of $5 \mathrm{G}$ network in these countries, the need for more base station sites to be built is even greater as $5 \mathrm{G}$ network has a short wavelength and requires higher number of sites [1]. Powering these sites with diesel generators is simply not sustainable. A thorough sizing work was previously done, and the result published in [2]. A rural base transceiver station site in Agbaja, in Kogi state of Nigeria was considered. The load data for the site was measured every 15 mins for one full year.

Submitted on March 29, 2021

Published on April 19, 2021.

Cyprian Oton, ECE, Faculty of Engineering and Applied Science, Memorial University, NL, Canada.

(e-mail: cnoton@mun.ca)
That data was used for the sizing the optimized system in HOMER pro. With this data, we are very sure that the entire scenario for the whole year is covered and the loss of load probability is very low since data is very crucial to a reliable sizing result. A $10 \%$ variability index was also incorporated into the sizing design to handle any variability in the load. The PV/Diesel/Battery configuration gave the least Net Present Cost (NPC) and least Cost of Energy (COE). The system showed an operating expenditure that was $75 \%$ less than the current configuration in the site with zero unmet energy.

\section{LITERATURE REVIEW}

There has been a significant level of research into the concept of powering base transceiver station sites with renewable energy sources both in standalone applications and hybrid systems configurations. These researches have been championed by both the academics and industry expert who daily strive to reduce the carbon footprint of telecommunication networks. In [3], a comparative analysis of a Solar-Powered base station for different generations of mobile communication technologies was examined for different system architecture. The operational expenditure (OPEX) saving was between $32 \%$ for 3 G Node B $4 / 4 / 4$ and $66 \%$ for $2 \mathrm{G} \mathrm{BS} 2 / 2 / 2$. The disadvantage of a single renewable source of power generation like solar here is the lack of reliability of renewable sources generally. Since seasonal variation is a major challenge, a hybrid configuration is always recommended.

In [4], an off-grid hybrid power system for a specific remote mobile base station located in Oromia, Ethiopia is considered. The study only carried out HOMER pro modeling, simulation, and techno-economic study. A feasibility study between was done between the optimized system and the closest hybrid configuration. Similarly, in an attempt to reduce the operation cost, the adverse effect of carbon emission on the environment and ensuring sustainability of base station (BS) power generation source, a feasibility study of a Solar Photovoltaic PV/Battery hybrid system to power a specific mobile cellular BS site in Soshanguve in Pretoria, South Africa was conducted in [5]. The dynamic behaviour of the system was studied using MATLAB/Simulink with very little component analysis.

In similar studies done in [6]-[8], the authors considered optimal sizing of various hybrid system configurations to power a mobile base transceiver station. Their studies focused on optimal sizing of the various systems with no form of

M. Tariq Iqbal, ECE, Faculty of Engineering and Applied Science, Memorial University, NL, Canada.

(e-mail: tariq ${ }^{\circledR}$ mun.ca) 
simulation to study the transient behaviour of these systems. The techno-economic analysis of various hybrid power system configurations is also a very widely studied topic in mobile base transceiver stations compared to the conventional power (diesel generator and grid) system [5], [9], [10]. These studies focus on the economics of using the hybrid system as opposed to the conventional system. Nothing is done with regards to the simulation of these system.

There is very limited literature with regards to dynamic simulation of various hybrid system to power a base station site. This paper is an attempt to bridge this gap and provide a detailed study of the various components of the hybrid system to power an outdoor base transceiver station site. The rest of the paper is focused on system sizing, dynamic model of the system, analysis of system components, simulation results a discussion and a conclusion is drawn.

\section{SYSTEM SIZING}

From the preliminary work published in [2], the optimal size of the system needed to power a base station site in a rural community in Nigeria consist of a $15 \mathrm{~kW}$ PV array, $3.6 \mathrm{~kW}$ DC diesel generator and 24 units of $12 \mathrm{~V}, 190 \mathrm{Ah}$ back up battery. A DC diesel generator is adopted for its high current capacity at low voltage. This is particularly useful for battery charging and powering the base transceiver station load which is DC in nature. The HOMER pro schematic model of the hybrid system showing the daily energy requirement, the peak load and the various components is shown in Fig. 1 and the electrical energy production summary with zero unmet energy and $89.4 \%$ renewable fraction is shown in Fig. 2.

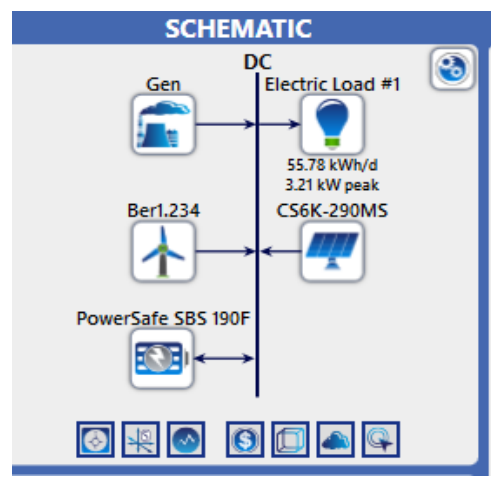

Fig. 1. HOMER pro schematic model of the hybrid system units.

\section{DYNAMIC MODEL OF SYSTEM}

To study the transient behaviour of the system, dynamic modeling and simulation is necessary to access the system response under varying load and resources, the system reliability and representation of the performance and operation. Dynamic simulation is an integral aspect of any engineering design in this modern era. This process eliminates the possibility of failure that may occur from actual implementation of the system in the field and saves cost of the prototype.

For this paper, MATLAB/SIMULINK is employed to simulate and analyze the different components of the system individually and then these components are integrated to form the whole system. Simscape, environment in Simulink is particularly useful in dynamic system modeling by representing the various system using the dynamic equation that describe the system [11]. The PV modules, DC-DC converters, battery, DC diesel generator and battery charge controller is analyzed in this work. The various components of the system are simulated and connected to form the hybrid system model. The model is shown in Fig. 3.
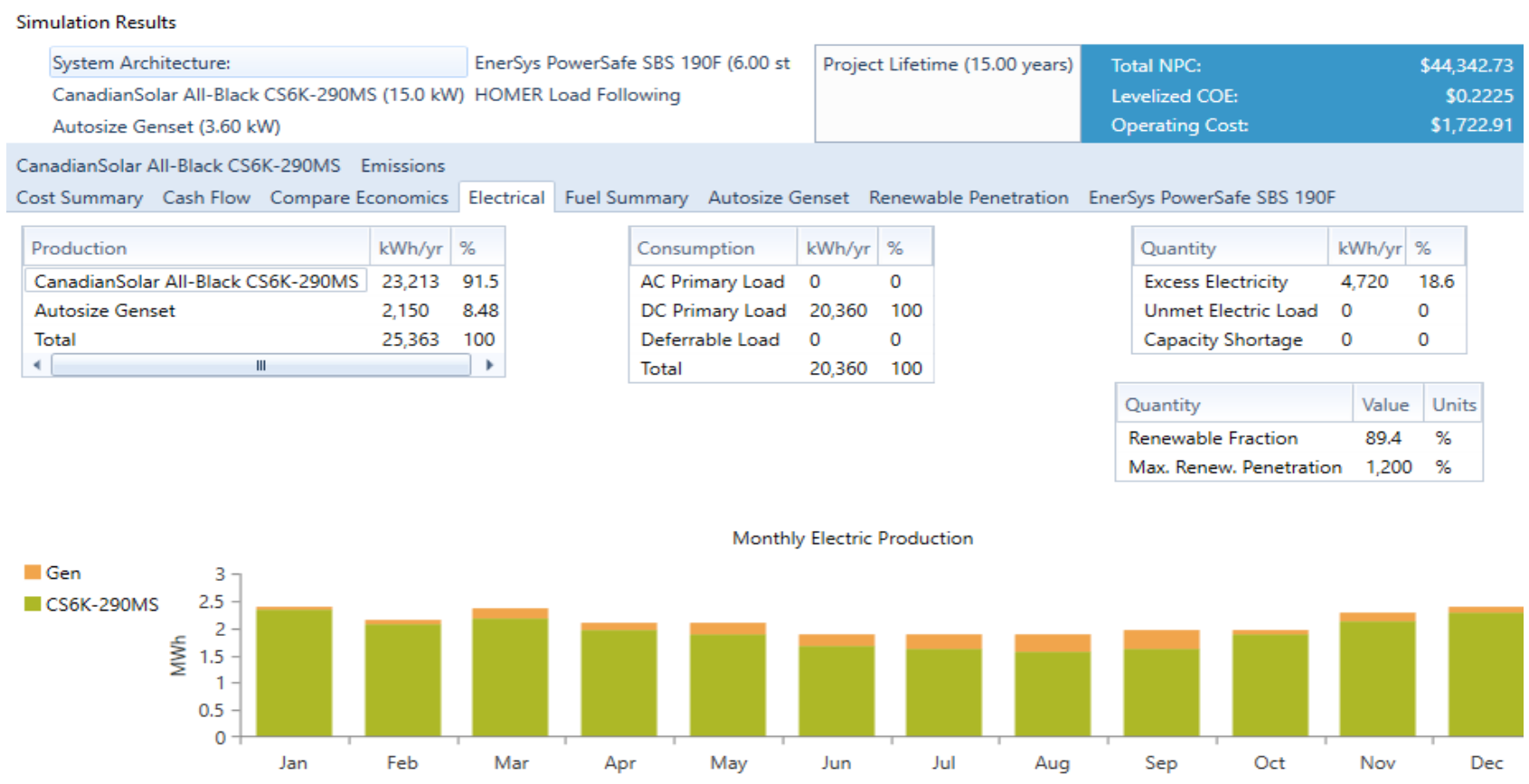

Fig. 2. Summary of electrical energy production in HOMER pro. 


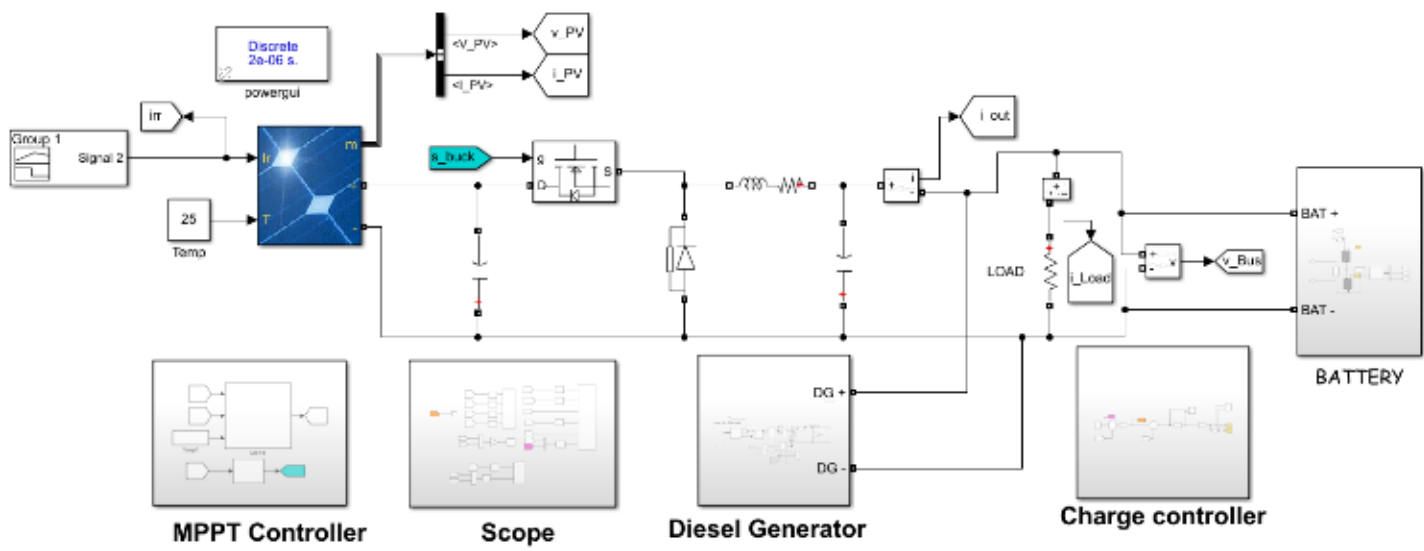

Fig. 3. Model of the hybrid system in Simulink.

\section{ANALYSIS OF DIFFERENT SYSTEM COMPONENTS}

\section{A. Solar Photovoltaic Array}

Solar PV operates by converting sunlight directly to electricity in a process known as photovoltaic effect. This process occurs when a photon of light is strikes the cell, creating an electron-hole pair movement. This movement causes current to flow in an external circuit connected to the cell. Since the voltage of this cell is usually very small (in the range of $0.5-0.8 \mathrm{~V}$ ), the cells are connected in series to increase the voltage and parallel to increase the current and this in turn, forms a module. The aggregation of this modules forms a panel, and the panels are connected in series and parallel as well to form an array. A two-diode model of a PV cell has better accuracy than the single diode model [12]. A constant ideality factor is assumed in a single diode representation. This value changes with a change in voltage. A two-diode model best captures this effect. The two-diode model is shown in Fig. 4 below. The equations that represent the various parameters of the circuit is summarized in (1) to (7) below [12].

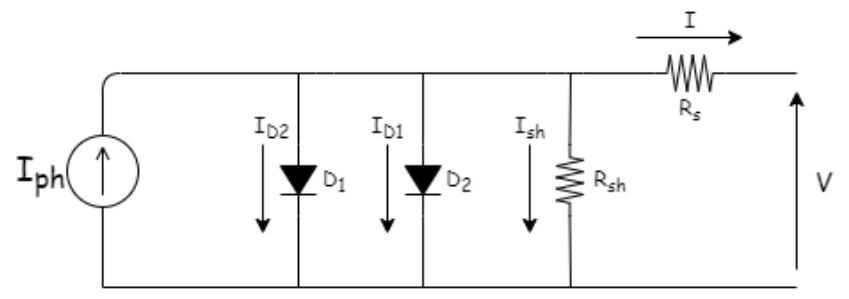

Fig. 4. Two-diode solar PV equivalent circuit model.

$$
\begin{aligned}
& I=N_{p} I_{p h}-N_{p} I_{D 1}-N_{p} I_{D 2}-I_{s h} \\
& I_{p h}=\left[I_{s c}+K_{i}\left(T-T_{r e f}\right)\right] G / 1000 \\
& I_{D 1}=I_{S}\left[e^{\frac{q\left(\frac{V}{N_{S}}+\frac{I R_{S}}{N_{p}}\right)}{n 1 k T-1}}\right] \\
& I_{D 2}=I_{S}\left[e^{\frac{q\left(\frac{V}{N_{S}}+\frac{I R_{S}}{N_{p}}\right)}{n 2 k T-1}}\right]
\end{aligned}
$$

$$
I_{s h}=\frac{\frac{N_{p v}}{N_{S}}+I R_{S}}{R_{S h}}
$$

$$
\begin{aligned}
& I_{S}=I_{r s}\left(\frac{T}{T_{r e f}}\right)^{3} e^{\frac{q E g\left(\frac{1}{T_{r e f}}-\frac{1}{T}\right)}{k n}} \\
& I_{r s}=\frac{I_{S c}}{e^{\left(\frac{q V O C}{N_{S} k T}-1\right)}}
\end{aligned}
$$

The current at the terminal of the PV cell is represented in (1). The current due to photon emission (photocurrent) is given in (2) and is expressed as a function of the solar irradiance and temperature. The current through diodes D1 and D2 is given (3) and (4) respectively. The shunt current and the series current are expressed in (5) and (6) respectively. The silicon contacts the metallic material and hence, creates a series resistance, Rs that reduces the current generated by the cell. Manufacturing defects accounts for the shunt resistance, Rsh which account for power losses in the cell by creating an alternate path for photocurrent current to flow. The reverse saturation current is given in (7). All the parameters used in the equations above are defined in Table I.

\section{B. Maximum Power Point Tracking (MPPT)}

Maximum power point tacking is implemented to continuously adjust the operating point of the solar PV array to the point of maximum power extraction by adjusting the impedance seen by the solar array continuously under varying irradiance, temperature and loading conditions. This is achieved by controlling array to operate at peak voltage. At this point, the power generated by the PV array is maximum for a given irradiance and temperature. Fig. 5. shows the schematic block diagram of most MPPT.

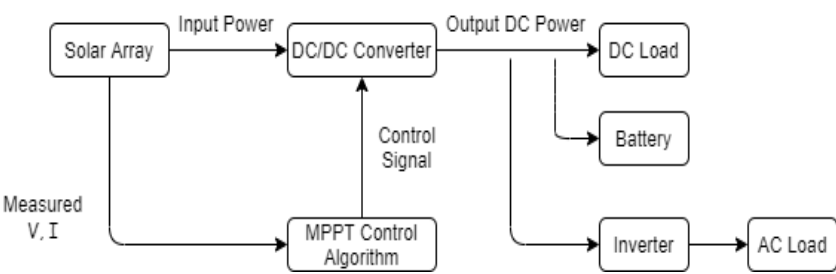

Fig. 5. MPPT schematic block 
TABLE I: PhOTOVOLTAIC MODELING CELL PARAMETERS

\begin{tabular}{ccc}
\hline Parameter & Description & Unit \\
\hline$I_{p h}$ & Photocurrent & $A$ \\
$G$ & Solar Irradiance & $W / \mathrm{m}^{2}$ \\
$I$ & Output current & $A$ \\
$E_{g}$ & Band gap energy & $1.3 \mathrm{eV}$ \\
$I_{D 1}$ & Current through diode 1 & $A$ \\
$I_{D 2}$ & Current through diode & $A$ \\
$R_{s}$ & Series resistance & $\Omega$ \\
$R_{s h}$ & Shunt resistance & $\Omega$ \\
$I_{r s}$ & Reverse Saturation current & $A$ \\
$I_{s}$ & Shunt current & $A$ \\
$I_{s c}$ & Short circuit current & $A$ \\
$I_{s h}$ & Shunt current & $A$ \\
$k$ & Boltzmann constant & $1.38 \times 10^{-23} \mathrm{~J} / \mathrm{K}$ \\
$K_{i}$ & Temperature coefficient of current & $\mathrm{A} /{ }^{\circ} \mathrm{C}$ \\
$n_{1}$ & Ideality factor of diode 1 & 1 \\
$n_{2}$ & Ideality factor of diode 2 & 1 \\
$q$ & Electron charge & $1.6 \times 10^{-19} \mathrm{C}$ \\
$T$ & Temperature of Solar cell & ${ }^{\circ} \mathrm{C}$ \\
$T_{r e f}$ & Temperature reference of cell & ${ }^{\circ} \mathrm{C}$ \\
$V_{o c}$ & Open circuit Voltage & $\mathrm{V}$ \\
$N_{p}$ & Number of parallel connected cell & $\mathrm{N}$ \\
$N_{S}$ & Number of series connected cell & $\mathrm{N}$ \\
\hline & &
\end{tabular}

The algorithm constantly monitors the operation point of the array by consistently measuring the output parameters (current and voltage) and using same as it input to adjust the duty cycle of the pulse width modulated (PWM) signal that controls the DC-DC converter switch [12].

For this work, the incremental conductance MPPT is utilized. This algorithm gives a higher degree of accuracy and efficiency than the perturb and observe method. It also yields a more stable result by ceasing to perturb the operating point resulting in one of the drawbacks of this method which is a higher response time [12]. The incremental conductance algorithm operates by comparing the incremental conductance, $d I_{p v} / d V_{p v}$ with the instantaneous $I_{p v}-V_{p v}$ characteristics of the solar array. The flowchart of the Incremental Conductance algorithm is shown in Fig. 6.

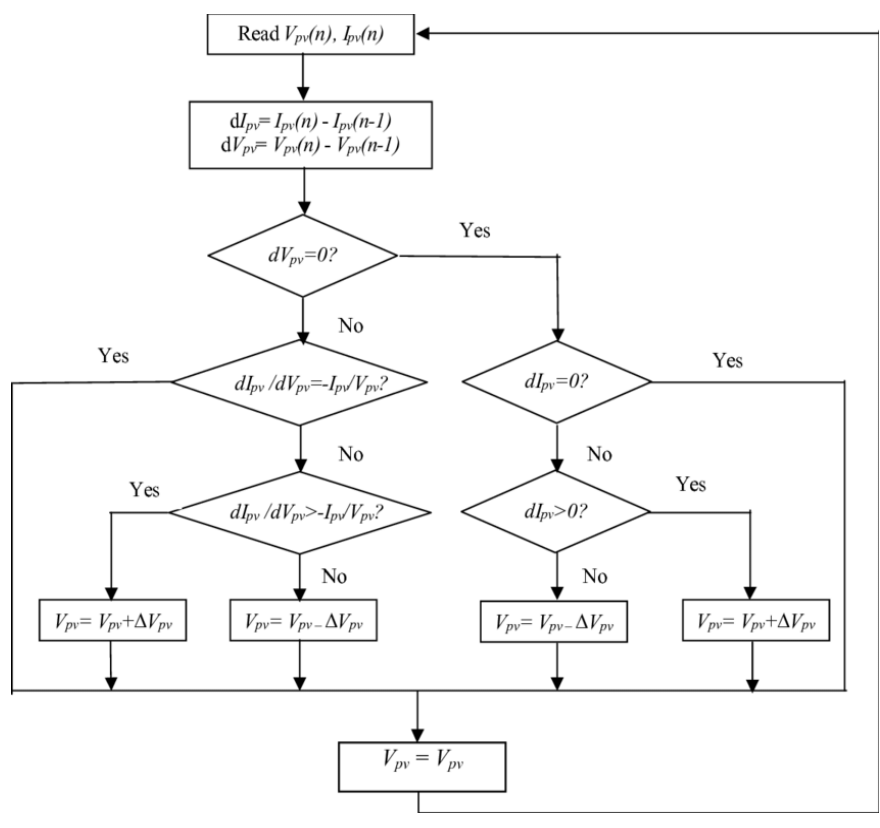

Fig. 6. Incremental Conductance algorithm flowchart.
At maximum power point (MPP), the change in power with respect to voltage is zero. This can be expressed as $\frac{d P_{p v}}{d v_{p v}}=$ 0 , since power is the product of voltage and current, the derivative can further be written as without the subscript as follows.

$$
\begin{gathered}
\frac{d P}{d V}=\frac{d(V . I)}{d V}=I \frac{d V}{d V}+V \frac{d I}{d V} \\
\frac{d P}{d V}=I+V \frac{d I}{d V}
\end{gathered}
$$$$
\frac{d I}{d V}=-\frac{I}{V} \text { at MPP }
$$

$\frac{d I}{d V}>-\frac{I}{V}$ at the left side of the MPP

$\frac{d I}{d V}<-\frac{I}{V}$ at the right side of the MPP

\section{Buck Converter}

DC-DC converters are used to convert from one voltage level to another to suit a particular purpose within the circuit. They are high-frequency power conversion circuits that operates by periodically opening and closing a switch [13]. The output voltage of a buck converter is lower than or equal to the input voltage, it is otherwise known as a step-down converter. These converters can operate either in Continuous Conduction Mode (CCM), where the inductor current remains positive throughout the switching period, or in discontinuous Conduction Mode (DCM), where the inductor current remains 0 for some time in the switching period. For this work, our converters will operate in CCM. Fig. 7 shows the buck converter circuit.

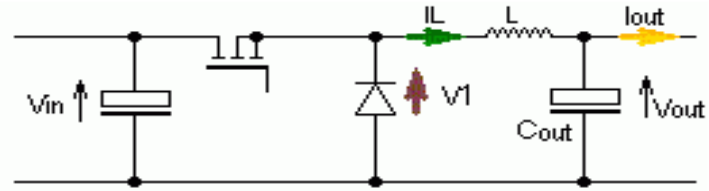

Fig. 7. Buck Converter Circuit.

The output voltage of the buck converter is related to the input voltage by (8) below.

$V_{\text {out }}=V_{\text {in }} * D$

The output voltage is $V_{\text {out }}$ and the input voltage is $V_{\text {in }}$ while the duty ratio is $\mathrm{D}$. The duty ratio represents the fraction of the commutation period during which, the switch of the converter is on. Its value ranges from 0 to 1 . The minimum inductor value for which the inductor current reaches zero is given in (9) [13].

$L_{\min }=\frac{(1-D) R}{2 f}$ 
$L_{\text {min }}$ is the minimum inductance required for continuous operation, $D$ is the duty cycle calculated at minimum input voltage, $R$ is the maximum load resistance and $f$ is the switching frequency. Any value of inductor lower than this minimum or critical value will cause the buck converter to operate in DCM which is undesirable. The buck converter design parameters for this work are summarized in Table II.

\begin{tabular}{cccc} 
& \multicolumn{3}{l}{ TABLE II: BUCK CONVERTER DESIGN PARAMETERS } \\
\hline \multirow{2}{*}{ Input } & $\mathrm{V}_{\text {in_min }}=48.0 \mathrm{~V}$ & $\mathrm{~V}_{\text {in_max }}=128.0 \mathrm{~V}$ & $\mathrm{~V}_{\text {in }}=128.0 \mathrm{~V}$ \\
& $\mathrm{~V}_{\text {out }}=48.0 \mathrm{~V}$ & $\mathrm{I}_{\text {out }}=314.17 \mathrm{~A}$ & $\mathrm{f}=5.0 \mathrm{kHz}$ \\
Result & $\mathrm{L}=53.60 \mathrm{uH}$ & $\Delta \mathrm{I}_{\mathrm{L}}$ for $\mathrm{V}_{\text {in_max }}=125.67 \mathrm{~A}$ & \\
\hline
\end{tabular}

$\mathrm{V}_{\text {in_min }}$ and $\mathrm{V}_{\text {in_max }}$ are the minimum and maximum input voltages, output voltage is $\mathrm{V}_{\text {out }}$ and output current $\mathrm{I}_{\text {out }}$ and $\mathrm{f}$ is the switching frequency. $V_{\text {in }}$ is the voltage used as input to sample the behaviour of the converter. The inductor value is $\mathrm{L}$ and the inductor current variation at maximum input voltage is given $\Delta \mathrm{I}_{\mathrm{L}}=0.4 \mathrm{I}_{\text {out }}$ for our design. The voltage and current responses of the buck converter is shown in Fig. 8 with the output voltage given as $48 \mathrm{~V}$ and the PV's input voltage at MPP given as $128 \mathrm{~V}$.

\section{Battery Storage System}

Energy storage is critical to the operation of a standalone microgrid that utilizes renewable energy. This is because renewable resources are variable in nature and fluctuates during different times of the day and year. Energy storage is what smoothens out this fluctuations and maintain output voltage stability [13]. Lead acid Battery serves as the storage in this study because of its high energy density when compared to other alternatives like supercapacitors. The response time for a supercapacitor on the other hand is quicker because the energy is not stored in a chemical form like in the battery. In DC microgrid, the response time is not as critical when compared to AC microgrid because of the absence of frequency regulation [13], [14]. Simulink models a battery as a non-linear voltage source where the output voltage depends on the current and the changing state of the battery (SOC). The SOC is a non-linear function of current and time [15]. Fig. 9. shows the model of the battery in Simulink. This model has internal resistance connected in series with a controlled voltage source.
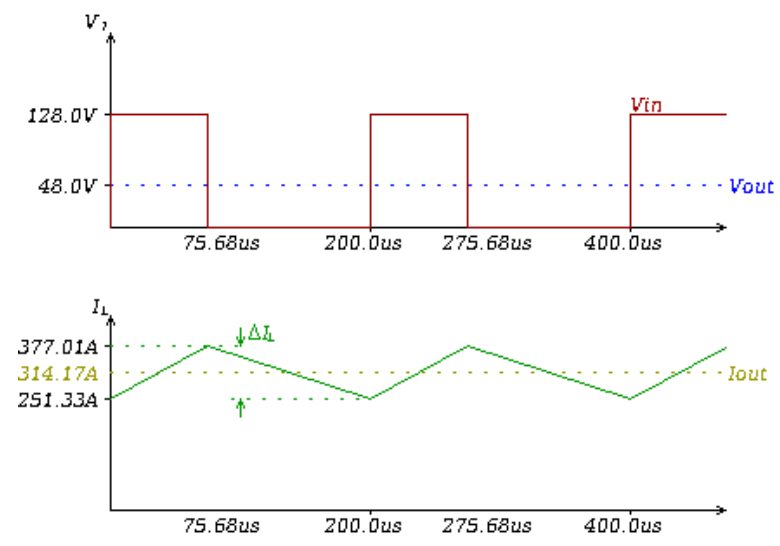

Fig. 8. Output Voltage and Current responses of the Buck Converter at MPP Voltage.

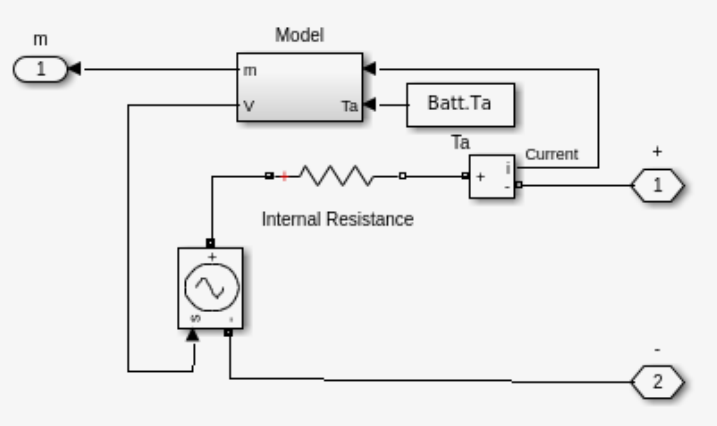

Fig. 9. Masked Battery model in Simulink.

The charging, discharging and the SOC of the battery can be modeled as follows [13], [16].

$$
\begin{aligned}
& E_{\text {charge }}=E_{0}-\frac{K Q i^{*}}{i_{t}+0.1 Q}-\frac{K Q i_{t}}{Q-i_{t}}+\text { Laplace }^{-1}\left(\frac{A}{s / B i_{t}+1} \cdot \frac{1}{s}\right) \\
& E_{\text {discharge }}=E_{0}-\frac{K Q i^{*}}{Q-i_{t}}-\frac{K Q i_{t}}{Q-i_{t}}+\text { Laplace }^{-1}\left(\frac{A}{s / B i_{t}+1} \cdot 0\right) \\
& S O C=100 *\left(1+\frac{\int i_{t} d t}{Q}\right)
\end{aligned}
$$

where $E_{0}$ is constant voltage $V, Q$ is the maximum battery capacity in $A h, K$ is the polarization constant in $A h^{-1}, i_{t}$ is extracted battery capacity $A h, i^{*}$ is the low frequency current dynamics in $A, B$ is exponential capacity $(A h)^{-1}$ and $A$ is the exponential voltage in $V$.

\section{E. Battery Charge Controller}

The charge controller is designed to operate by comparing the actual bus voltage, $V \_B u s$ to the reference voltage $V \_R e f$ which is $48 \mathrm{~V}$. The error which is the difference between $V_{-}$Bus and $V_{-}$Ref is fed into a PI controller. The output of the PI controller gives the battery reference current $I B \_$Ref and this is compared with the actual battery current $I \_B a t$ forming the inner current loop. The deviation is adjusted by a PI controller and fed to the IGBT switch through a PWM signal. Boost switch is activated for an increase in $V_{-} B u s$ and buck switch for a decrease in $V_{-}$Bus. as shown in Fig. 10 .

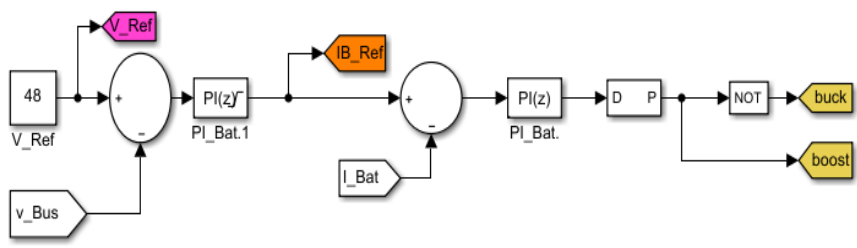

Fig. 10. Charge controller topology for the Battery.

\section{F. Diesel Generator}

Diesel generator (DG) is employed as a backup power supply when the battery state of charge (SOC) goes below the minimum safe operating value. The DG is in operation when the solar power is not available, and the backup battery has discharged to it minimum operating SOC of 45\%. A permanent magnet synchronous generator (PMSG) employed for this project for its high efficiency, its current production at low voltages and minimal losses. Rectification of the AC generated by the PMSG is done internally using a diode 
bridge and a smoothening capacitor. The power is then used to charge the battery and supply the load instantly or later. The model of the PMSG in the d-q coordinate (rotor reference frame) where all quantities in the rotor reference are referred to the stator is given by [17], [18].

$$
\begin{aligned}
& \frac{d i_{d}}{d t}=\frac{1}{L_{d}} v_{d}-\frac{R}{L_{d}} i_{d}+\frac{L_{q}}{L_{d}} p \omega_{m} i_{q} \\
& \frac{d i_{q}}{d t}=\frac{1}{L_{q}} v_{q}-\frac{R}{L_{q}} i_{q}+\frac{L_{d}}{L_{q}} p \omega_{m} i_{d}-\frac{\lambda p \omega_{m}}{L_{q}} \\
& T_{e}=\frac{3}{2} p\left[\lambda i_{q}+\left(L_{d}-L_{q}\right) i_{d} i_{q}\right]
\end{aligned}
$$

The subscript $\mathrm{d}$ and $\mathrm{q}$ are the physical quantities that has been transformed into the $\mathrm{d}-\mathrm{q}$ rotating frame. Table III defines the parameters of the PMSG.

\section{TABLE III: PMSG PARAMETERS}

\begin{tabular}{cl}
\hline$L_{q}, L_{d}$ & $q$-axis and $d$-axis inductances of the generator $(\mathrm{H})$ \\
$R$ & Resistance of the stator windings $(\Omega)$ \\
$i_{q}, i_{d}$ & $q$-axis and $d$-axis currents (A) \\
$v_{q}, v_{d}$ & $q$-axis and $d$-axis voltages $(\mathrm{V})$ \\
$\omega_{m}$ & Angular velocity of the rotor $(\mathrm{rad} / \mathrm{s})$ \\
$\lambda$ & $\begin{array}{l}\text { Amplitude of the flux induced by the permanent } \\
\text { magnets of the rotor in the stator phases }\end{array}$ \\
$p$ & Number of pole pairs \\
$T_{e}$ & Electromagnetic torque (N.m) \\
\hline
\end{tabular}

\section{G. Load}

The load for the system was selected as a resistive load since telecoms load is DC in nature. The simulation is carried out for a peak power demand of $3.2 \mathrm{~kW}$ and this translate to a resistor value of $0.72 \Omega$ on a bus voltage of $48 \mathrm{~V}$. Peak value is considered to ensure the simulated system can withstand the highest load requirement.

\section{Simulation Results AND DisCUSSION}

This model is simulated for 5 seconds to study the transient behaviour of the system. The parameters of the system like output voltage, current of PV, battery SOC, bus voltage and other relevant parameters of interest are observed using scopes. Fig. 11 shows the graph of PV's output voltage, current, buck converter output current and DC bus voltage. The output PV voltage is at MPPT (128 V) for variable irradiance values other than zero. This demonstrates the effectiveness of the MPPT algorithm. The current changes to reflect the irradiance the $\mathrm{PV}$ is exposed to. The buck converter is designed to give output voltage of $48 \mathrm{~V}$.

Fig. 12 (a) shows the solar irradiance, PV output power and battery state of charge (SOC). Between 0-1.5 s, an irradiance of $200 \mathrm{~W} / \mathrm{m}^{2}$ is applied to the solar array, a power of $2.8 \mathrm{~kW}$ is generated, this power is not enough for the load, the battery is discharged from an initial $70 \%$ SOC to support the load. Between $1.5 \mathrm{~s}-2 \mathrm{~s}$, an irradiance of $600 \mathrm{~W} / \mathrm{m}^{2}$ is enough to supply the load and the remaining power is used to charge the battery. Between $2 \mathrm{~s}-3 \mathrm{~s}$, maximum irradiance of $1000 \mathrm{~W} / \mathrm{m}^{2}$ is applied to the PV and the output power of the PV is $15 \mathrm{~kW}$ which correspond to the power at MPPT. Between $4 \mathrm{~s}-5 \mathrm{~s}$, there is no irradiance applied to the PV and hence, no power generated from the PV. The load is supplied entirely by the battery, hence the reduction in the SOC of battery.

When the solar array is not producing power and the state of charge of the battery is less than $45 \%$, the diesel generator is activated to supply the load. This generator is sized to power the load primarily while relying mostly on solar power to charge the battery because of load following dispatch strategy employed in HOMER pro during sizing. This dispatch strategy prioritizes battery charging using renewable resource, in this case solar power.

Fig.12 (b) shows the battery current, battery SOC and the output DC bus voltage following the reference bus voltage. When the battery is discharging (between $0-1.5 \mathrm{~s}$ and $4 \mathrm{~s}-$ $5 \mathrm{~s}$ ), the battery current is positive. When the battery charging $(1.5 \mathrm{~s}-4 \mathrm{~s})$, the current is negative. The battery regulates the effect of the varying irradiance and maintains a constant output bus voltage by either charging or discharging depending on the solar resource available to the solar array.

The simulated system can supply a stable power output despite the variability of the solar resource. Fig. 13 shows the load current, and the power delivered to the load at a constant voltage. The current drawn by the load is constant at $66.7 \mathrm{~A}$ at a bus voltage of $48 \mathrm{~V}$.

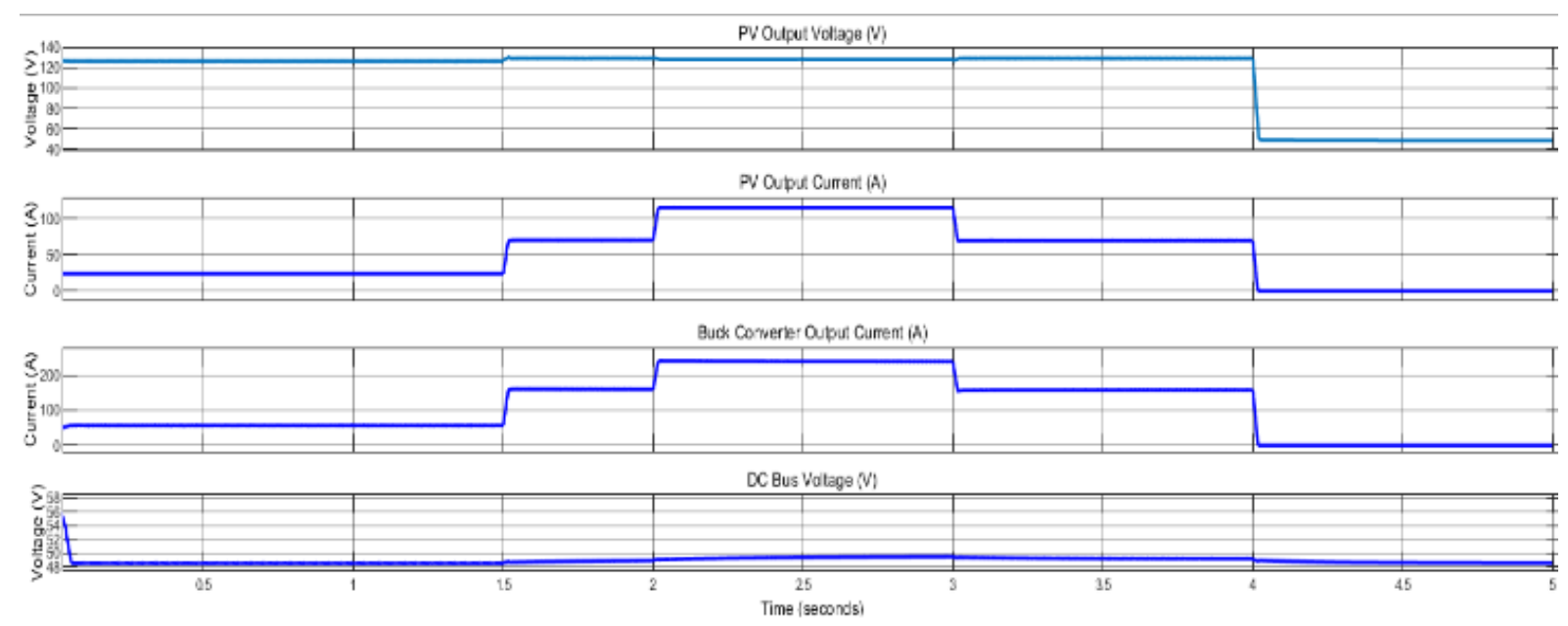

Fig. 11. PV voltage, Current, buck converter current and DC bus voltage. 

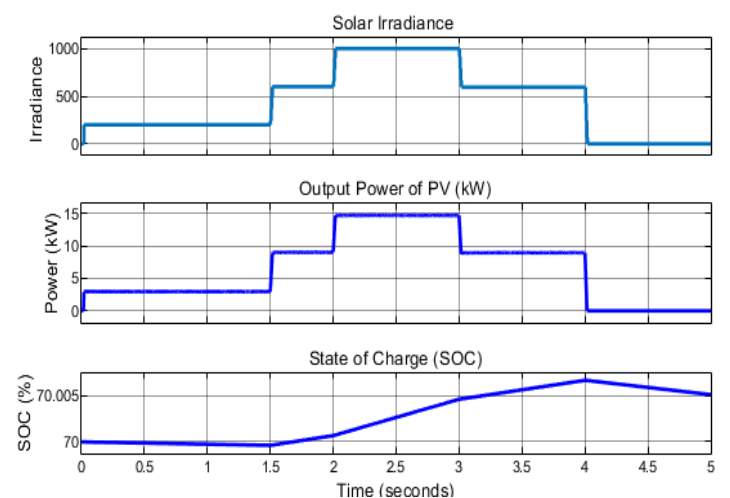

(a)
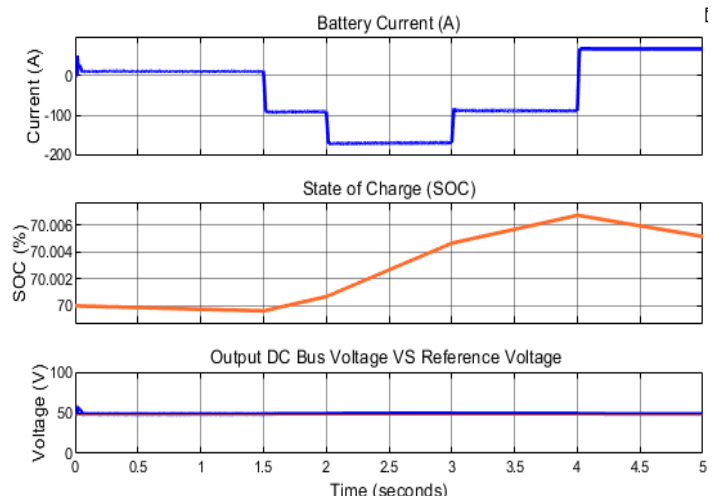

(b)

Fig. 12. (a) Solar Irradiance, PV output power and SOC of battery; (b) Battery current, SOC and DC bus voltage.
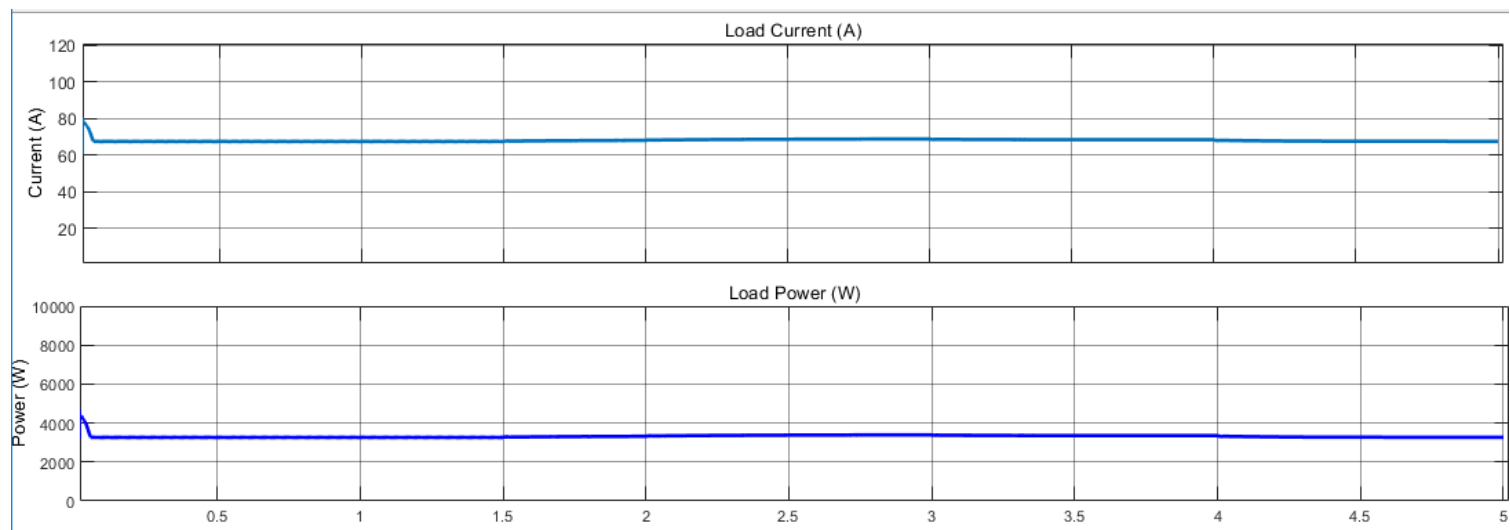

Fig. 13. Load current and load power.

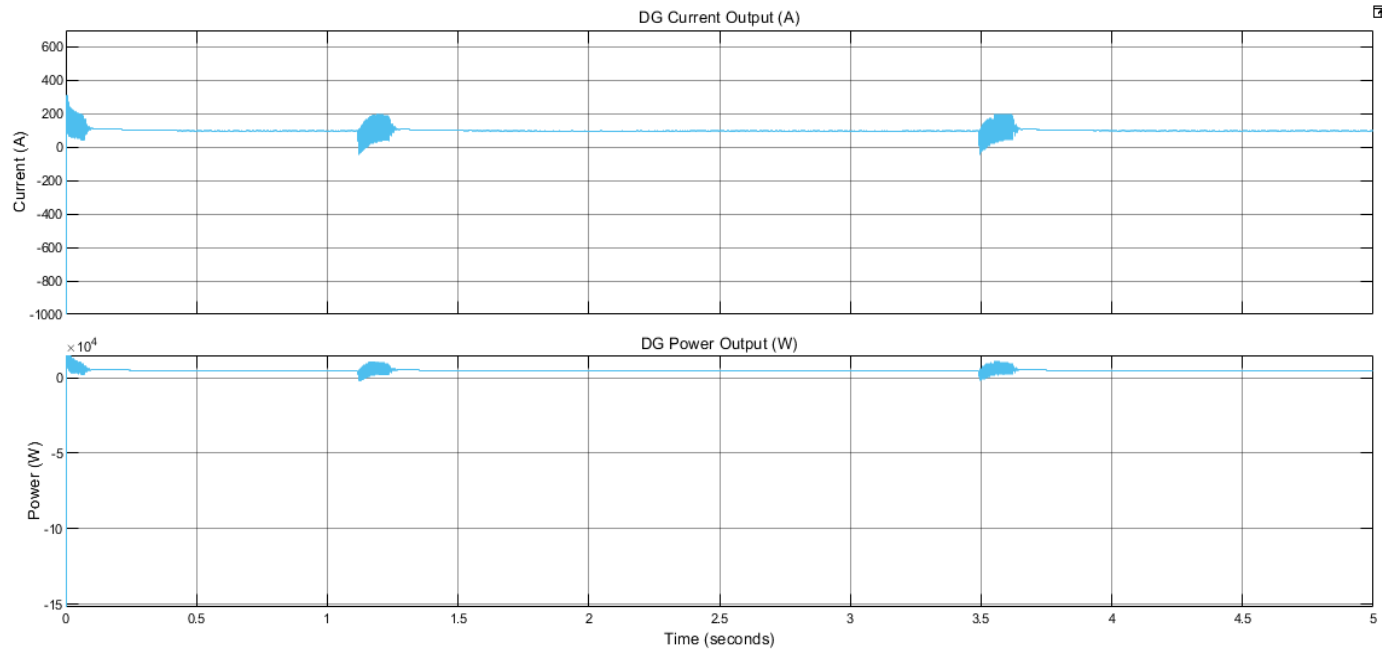

Fig. 14. Rectified diesel generator output current and power.

Fig. 14 shows the rectified current output of the diesel generator at a constant voltage of $48 \mathrm{~V}$ and the power with minor ripples caused by the harmonics in the PMSG output. The battery is absorbing the excess power from the diesel generator after supplying the load, hence the negative battery current, meaning the battery is charging as seen in Fig. 15.

The power supplied to the load due to the diesel generator is seen in Fig. 16.

The current absorbed by the load is 66.7 A similar to when the PV supplied the load.
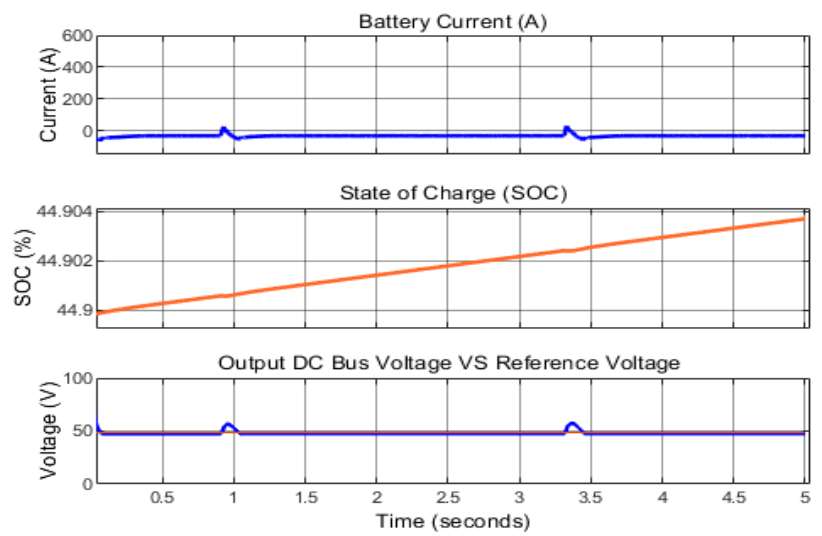

Fig. 15. Battery charging current, SOC and output DC voltage due to diesel generator. 


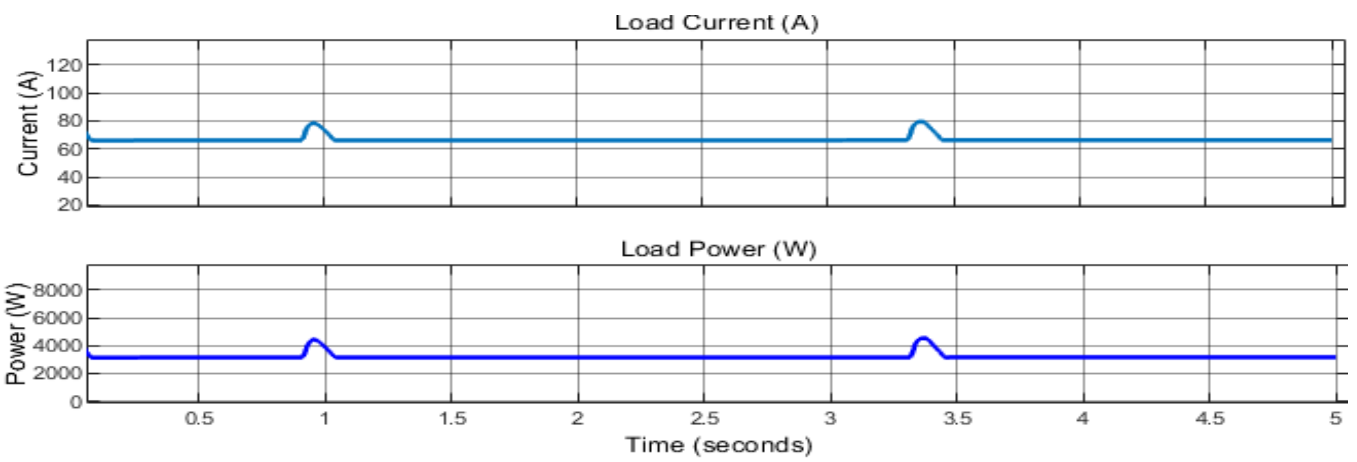

Fig.16. Output current and power due to diesel generator

\section{CONCLUSION}

The modeling and simulation of a DC hybrid power system for powering a base transceiver station was studied in this paper. The system was simulated under varying solar irradiance and the result obtained was observed using scopes. The MPPT algorithm worked to keep the voltage at its MPP for varying irradiance values and maximum power was extracted from the PV. The dc-dc buck converter steps down the voltage to the required level with higher output current. The result also showed that the battery storage system absorbed excess energy during periods of high energy production and gave out energy during periods of low/no energy production. The diesel generator was able to inject a predetermined constant power to the system to supply the load and charge the battery during periods of no solar irradiance and low SOC of battery. The SOC for which the battery is cut-off and generator kick in is $45 \%$. The studied system showed a satisfactory response and can provide a stable power to the load. For future studies, a low-cost, open source IoT-based supervisory control and data acquisition system (SCADA) will be implemented to log historical data for the system and provide control for the system remotely.

\section{ACKNOWLEDGMENT}

The authors would like to thank the School of Graduate Studies, Faculty of Engineering and Applied Science, Memorial University of Newfoundland, Canada for providing the enabling environment for carrying out this research and The Niger Delta Development Commission (NDDC) of Nigeria for providing the financial support for this study. (Grant No. NDDC/DEHSS/2016PGFS/AKS/002).

\section{REFERENCES}

[1] R. Gavrić, D. Ilišević, N. B. Curguz, and B. đ, "Comparison of basic characteristics of 4G/LTE and 5G NR technology," in 2019 27th Telecommunications Forum (TELFOR), 2019, pp. 1-4.

[2] C. Oton and M. T. Iqbal, "Design and Analysis of a Stand-alone DC Hybrid Microgrid for a Rural Base Transceiver Station in Nigeria," in 2020 IEEE Electric Power and Energy Conference (EPEC), 2020, pp. $1-6$.

[3] H. A. Mohammed, "Comparative Analysis of Solar-Powered Base Stations for Green Mobile Networks," Energies, vol. 10, no. 8, p. 1208, 2017.

[4] T. Y. Mulualem and K. Baseem, "Design of an off-grid hybrid PV/wind power system for remote mobile base station: A case study," AIMS Energy, vol. 5, no. 1, pp. 96-112, 2017.
[5] B. Aderemi, S. Chowdhury, T. Olwal, and A. Abu-Mahfouz, "TechnoEconomic Feasibility of Hybrid Solar Photovoltaic and Battery Energy Storage Power System for a Mobile Cellular Base Station in Soshanguve, South Africa," Energies, vol. 11, no. 6, p. 1572, 2018.

[6] V. A. Ani, "Optimal Operational Strategy for PV/Wind-Diesel Hybrid Power Generation System with Energy Storage," ed, 2017, pp. 1438 1460.

[7] L. J. Olatomiwa, S. Mekhilef, and A. S. N. Huda, "Optimal sizing of hybrid energy system for a remote telecom tower: A case study in Nigeria," ed, 2014, pp. 243-247.

[8] M. H. Alsharif, R. Nordin, and M. Ismail, "Optimization of hybrid renewable energy power system for urban LTE base station deployment in Malaysia," in 2014 IEEE 2nd International Symposium on Telecommunication Technologies (ISTT), 2014, pp. 1-5.

[9] L. Olatomiwa, S. Mekhilef, A. Huda, and K. Sanusi, "Technoeconomic analysis of hybrid PV -diesel-battery and PV -wind-dieselbattery power systems for mobile BTS : the way forward for rural development," Energy Science \& Engineering, vol. 3, no. 4, pp. 271 $285,2015$.

[10] M. Alsharif, "Techno-Economic Evaluation of a Stand-Alone Power System Based on Solar Power/Batteries for Global System for Mobile Communications Base Stations," Energies, vol. 10, no. 3, p. 392, 2017.

[11] C. Li, "Development of Simscape Simulation Model for Power System Stability Analysis," ed: IEEE, 2012, pp. 1-4.

[12] T. Ahmad, S. Sobhan, and F. Nayan, "Comparative Analysis between Single Diode and Double Diode Model of PV Cell: Concentrate Different Parameters Effect on Its Efficiency," Journal of Power and Energy Engineering, vol. 04, pp. 31-46, 01/01 2016.

[13] J. A. Grant, "Design and Simulation of a DC Microgrid for a Small Island in Belize," 2018.

[14] X. Tan, Q. Li, and H. Wang, "Advances and trends of energy storage technology in Microgrid," International Journal of Electrical Power \& Energy Systems, vol. 44, no. 1, pp. 179-191, 2013/01/01/ 2013.

[15] V. Madhavi, "Modeling and Coordination Control of Hybrid AC/DC Microgrid," 2014

[16] B. Jiang and M. T. Iqbal, "Dynamic Modeling and Simulation of an Isolated Hybrid Power System in a Rural Area of China," Journal of Solar Energy, vol. 2018, p. 5409069, 2018/06/03 2018.

[17] B. Farhan, S. Wang, and H. Wahhab Rabee, "Control of Variable Speed Diesel Generator using FOC in Hybrid System," International Journal of Control and Automation, vol. 9, pp. 111-122, 10/31 2016.

[18] A. Rolan, A. Luna, G. Vazquez, D. Aguilar, and G. Azevedo, "Modeling of a variable speed wind turbine with a Permanent Magnet Synchronous Generator," in 2009 IEEE International Symposium on Industrial Electronics, 2009, pp. 734-739.

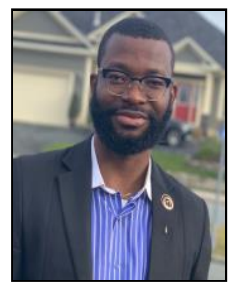

Cyprian Oton was born in Nigeria and received his B. Eng. degree in Electrical/Electronics Engineering from The University of Uyo, Nigeria in 2013. He had his mandatory national service in Afam Power PLC, an electricity generating company between 2013 2014. Between 2015-2018, he worked as a field maintenance engineer for Allstreams Energy Solutions Limited, servicing Airtel Nigeria. He has also had an internship with Mobil Producing Nigeria Unlimited, a subsidiary of ExxonMobil in 2011. He is currently pursuing an M. Eng. degree in Electrical Engineering at Memoria University of Newfoundland, Canada. His research is focused on design and control of hybrid power system for a remote location in his country Nigeria. 


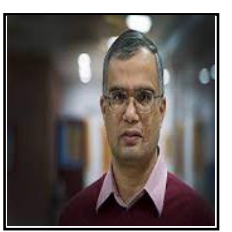

M. Tariq Iqbal completed his B.Sc. (EE) at University of Engineering and Technology, Lahore in 1986, his M.Sc. Nuclear Engineering at CNS, Quaide- Azam University, Islamabad in 1988 and his Ph.D. in Electrical Engineering at Imperial College London in 1994. From 1988 to 1991 and again from 1995 to 1999, he worked at Pakistan Institute of Engineering and Applied Sciences (PIEAS), Islamabad. From 1999 to 2000, he worked as an Associate Professor at Riphah International University. Since 2001, he has been working at Faculty of Engineering and Applied Science, Memorial University of Newfoundland. Currently, his research focuses on modeling and control of hybrid renewable energy systems and he has strong interest in consumer electronics and instrumentation. 